\title{
Exchange Sex, the Perfect Job, Understanding the Exchange of Sex for Money: The Concept of Partial Happiness, Total Happiness and the New Concept of Supra-Happiness
}

\author{
Richard Joseph Wix-Ramos \\ Wixbiotech, CA, Naguanagua, Venezuela \\ Email: richardwixramos@gmail.com
}

How to cite this paper: Wix, R.J. (2021) Exchange Sex, the Perfect Job, Understanding the Exchange of Sex for Money: The Concept of Partial Happiness, Total Happiness and the New Concept of Supra-Happiness. Advances in Sexual Medicine, 11, 59-72.

https://doi.org/10.4236/asm.2021.113004

Received: May 3, 2021

Accepted: July 27, 2021

Published: July 30, 2021

Copyright ( 2021 by author(s) and Scientific Research Publishing Inc. This work is licensed under the Creative Commons Attribution International License (CC BY 4.0).

http://creativecommons.org/licenses/by/4.0/ (c) (i) Open Access

\begin{abstract}
According to Freud, Happiness is defined as the discharge of sexual drive (Orgasm); obtaining happiness usually costs a lot of energy for women and even more for men, but what happens when that happiness is obtained without energy expenditure, when happiness is obtained with gain of energy or money. Exchange sex is defined as the exchange of sex for energy (in this case money), nevertheless, the classic normal relationships between men and women in society function in general as an exchange of sex for energy (money). So it could be argued that relationships between men and women in our society function on the basis of exchange sex. However, the intrapsychic conflict of individuals complicates and makes it difficult to achieve that happiness. We will also analyze the way to obtain Partial Happiness (get orgasms with people you are not in love with), Total Happiness (get orgasms from the people you are in love with), and a new concept The Supra-Happiness (get orgasms from many attractive people simultaneously; even if you are fall in love with these people or not). That happiness is only temporary, the original dissatisfaction and lack of the human psyche has to be filled and constantly satisfied with that temporary happiness.
\end{abstract}

\section{Keywords}

Exchange Sex, Sex, Happiness, Money, Couple Relationships 


\section{Introduction}

\subsection{Difference between the Exchange Sex and the Classic Normal Couple Relationships between Men and Women}

\subsubsection{Advantages of Sex with Sex Worker Instead of Classic Normal Couple Relationships}

The classic normal couple relationships are established on temporary monogamy, while in classical exchange sex the relationship is generally polygamous. That monogamy is a disadvantage for men, since men are by nature polygamous [1]; women are equally polygamous but need the exchange of male partners less often than men; women need a man for the fertilization of the child every 9 months in reproductive age; then they need a couple to stay to guarantee the food and protection of the offspring (that couple is usually the father; men reject the protection and care of the offspring when they do not have their own genes); that time of care of the man lasts from 3 to 5 years; after that time the woman can look for another couple. Men on the other hand can fecundate several women a day, so the frequency of exchange of partners can be much greater than that women. The establishment of the classic monogamy relationship would be a disadvantage for men.

In the classic normal couple relationships, the sexual practice quality is poor; sexual practice with sex worker is high quality. Generally, sexual practice with a sex worker is high quality since it is developed by a professional in the field, while sexual relations in a classic normal sexual relationship are developed by a woman who is not a professional in sexual practice; in addition, the frequency of sexual desire in man in general is greater than in women [2], so if it depends on the exclusive sexual desire of women for having sex in the classic normal relationships, the man will be constantly frustrated.

The classic normal couple relationships are of lower quality than the sexual practice with sex worker since in general the physical attractiveness is greater in the sex worker. Without physical attractiveness, the sexual desire diminishes; in exchange sex, the service that is offered is better quality because of physical attractiveness; the sex worker must be in general attractive naturally or by artificial means as physical exercises, cosmetics or plastic surgeries.

In the classic normal couple relationships, there is more suffering and unhappiness than sexual practice with sex worker. In the classic normal couple relationships, the discharge of frustration, anger, resentment, hatred and all other negative, violent and aggressive death instincts, tend in general to be discharged on the nearest people, in this case the couple. While in sexual practice with sex worker, only pleasure, happiness, satisfaction, joy, and all other erotic sexual drives are obtained; in general in the sexual setting with a sex worker, there is no place for aggressive impulses.

In theory, men to achieve partial and temporary happiness would be to have relationships with sex worker and not classic couple relationships, which are usually monogamous (something unnatural). Sexual practice with sex worker is 
more pleasant, of better quality and the frequency will depend on the sexual desire of the man not the woman.

\subsubsection{Disadvantages of Sex with Sex Worker Instead of Classic Normal Relationships}

True happiness is the discharge of sexual drive (orgasm) and much better when that orgasm is over the object where you have the libido (the person you love and you are in love with). The real happiness is usually the sexual relationship with a normal classic couple relationship, not with a sex worker, the discharge of sexual drive with a sex worker is satisfying and pleasurable, but it is a partial satisfaction, not total as when you have sex with the person you love. However, it is important to clarify that not all normal couple relationships are established with love, many of them are established for other reasons (loneliness, money, sperm donor for procreation, etc.) and not just for love. The other important aspect is that total happiness (having sex with the person you love, in this case, usually with a classic couple relationship) is temporary (lasts a limited time: from 6 months to 5 years with 1 child) and not infinite and timeless. Also put the libido on an object (fall in love with someone) is the total happiness but it is also dangerous, if the person who you puts the libido (the person who is in love with) does not correspond that love, abandons, is unfaithful or dies, the risk of suffering, pain, depression that causes the loss is very high [3].

Sexual practice with sex worker is not free, there is an exchange of energy to obtain pleasure and happiness, however the cost of sex with sex worker despite not being free, is relatively inexpensive and accessible to practically any man. It is important to note that although sexual intercourse with sex worker is not free, it is usually more economical than the usual normal relationships, where you have to invest a large amount of money in the relationship, the expenses of the children and the family in general. So even though it seems a disadvantage sexual practice with sex worker is usually preferable to the classic normal relationships.

\subsection{Energy Exchange Balance (Sex for Money)}

The exchange of energy (sex for money) that occurs between sex worker and clients or classic normal couple relations, is lowered by the laws of the market, sex is a precious, scarce; therefore men are willing to invest energy (money) to get sex. The reason for this is that the demand for sex by women is much lower than that of men, tehrefore the price of sex increases. However in the intrapsychic conflict conscious or subconscious, this exchange of sex for money is interpreted by men like market speculation, men think: why the exchange is not sex for sex?, men do not understand at the subconscious or conscious level the laws of the market, which generates extreme violence in relationships (infidelity, abandonment, violence of any kind, apathy) [4]. 


\section{Social Rejection of Sex Worker and Men Who Obtain Partial Happiness with Sex Worker}

Society generally rejects sex worker since, as a concept, it is an antisocial structure, let us imagine for a moment that women with strong psyche practiced exchange sex and men requested it without any legal or social restraint, this would imply that a single woman of high quality (attractive, with good sexual performance, economic, polygamous, a different sex worker in each orgasm), thus would only generates partial happiness and not suffering. This would mean that no man would commit to a stable relationship with any woman, no kind of responsibility to the children, which would be very disadvantageous and problematic from the society, women in general totally reject sex worker because it is an unfair competition. In case of men, if all women practice exchange sex (obtaining energy or money to guarantee the subsistence of the offspring) as a profession and not in the social constellation as a normal relationship (where energy or money is obtained in exchange for sex with a stable partner), this would generate that few men could guarantee their genetic legacy over time, given that women with the money or energy could choose high quality men (attractive and smart) as the biological parents of their children, they would not depend on men of low quality (unattractive) to ensure the subsistence of the species, so that men reject sex worker as a generalized social practice.

The archetype of Don Juan or Casanova or the Amazon or Nymph is equally rejected by society, men or woman who obtains Partial Happiness, Total Happiness or Supra-Happiness with many relationships without any responsibility, without children or offspring it is an antisocial structure, if it would practiced in general by all the people would generate many difficulties and problems in the society, for that reason those structures are strongly rejected.

Some societies likewise reject the exchange sex (the offer) or the request of the exchange sex (the clients) to diminish the possibility of sexual slavery, when the legislation considers it a crime, then the forced practice or the sexual slavery can be controlled more easily. Some advanced societies allow exchange sex legally with less risk of sexual slavery or forced practice, because social, police, legal systems are so efficient that there is little risk of sexual slavery or forced practice. In countries with vulnerable judicial, police and social systems, all the attention must be paid and all available means must be employed to eliminate any forced practice or any type of sexual slavery [5].

\section{Concept of Partial Happiness, Total Happiness and Supra-Happiness Concept}

Partial Happiness: is defined as the discharge of sexual drive on any object (get an orgasm with someone who is not in love with). That happiness is only temporary, the original dissatisfaction and lack of the human psyche has to be filled and constantly satisfied with that temporary partial happiness.

Total Happiness: is defined as the discharge of sexual drive on an object 
where the libido is placed (get an orgasm with someone you are in love with). That happiness is only temporary, the original dissatisfaction and lack of the human psyche has to be filled and constantly satisfied with that temporary happiness.

Supra-Happiness: I defined as the discharge of sexual drive on an object where you have the libido or several objects where the libido is placed simultaneously or objects where they are not put the libido but good quality (get an orgasm with someone you are in love with or with several people you are in love with or people you are not in love with but of high quality: attractive, interesting, with good performance in sexual practice, with money or whatever the fantasy of desire). That happiness is only temporary, the original dissatisfaction and lack of the human psyche has to be filled and constantly satisfied with that temporary supra-happiness.

Other important point of discussion would be to discern whether the discharge of the sexual drive on objects, where you do not have libido but high quality (get orgasms from several people simultaneously who are not in love but are attractive or with characteristics of the fantasy of desire) generates more happiness than the discharge of the sexual drive on the object where you has the libido but of low quality (to obtain an orgasm of the person who is in love but low quality: less physical attractiveness, less fantasy of desire). Since the libido is transferred from one object to another in a massive and immediate way [6], the libido would quickly pass from the low-quality object (unattractive or without fantasy of desire) to the object or high-quality objects (attractive or fantasies of desire). In that case, the supra-happiness is obtained by discharge the sexual drive on high quality objects that have not yet been given libido. The disadvantage with this hypopthesis is that in theory it is feasible but difficult to perform. It is expensive to discharge the sexual drive on one or more quality objects (get orgasms from one or several attractive people at the same time). If you have the money and could theoretically access the object of high quality, the objects generate jealousy and possessive behaviors, the monogamous possessive behaviors generate violence in the relationship which diminishes happiness. In theory practice the discharge of sexual drive on one or more high quality objects at the same time has to be implemented very carefully.

\section{Exchange Sex as the Perfect Job to Achieve Supra-Happiness}

If total happiness is obtained by discharge the sexual drive on the object where the libido is placed (obtaining an orgasm from the person who is in love with), then exchange sex would theoretically be the perfect job to achieve total happiness and supra-happiness. It would be enough only during the practice of exchange sex to discharge the libido on the object where the libido is placed (to obtain an orgasm of the person who is in love) and to reach the supra-happiness to discharge the sexual drive on the object where it is placed the libido or on 
several high quality objects (get an orgasm from people who are in love or several attractive people or with characteristics of object of desire), and in addition to achieving happiness and supra-happiness you would get additional money with the practice of exchange sex (money is an additional added value and probably the most important to achieve total happiness and supra-happiness).

\section{Difficulties to Obtain Total Happiness and Supra-Happiness through Exchange Sex}

Theoretical, in exchange sex money would be obtained and in addition total happiness or supra-happiness, however in practice it is difficult to get orgasms from people who are in love or attractive people at the same time, usually individuals generate monogamous relationships possessive, jealous, that make it difficult to discharge the simultaneous sexual drive on many objects (orgasms with several people at the same time), and sexual drive discharges on high quality objects simultaneously is financial expensive (orgasms with several attractive people at the same time).

Other problem is that in theory, exchange sex would be the perfect job to obtain total happiness and supra-happiness but in practice, the quality of clients of sex worker is very low (unattractive people) which makes it difficult to discharge of sexual drive in the case of women and only partial happiness in men (sex with unattractive people hinders orgasm in women and orgasm in men is less satisfying than with physically attractive ones).

Sex worker get the company of men during the practice of their profession, if they feel alone, this company partially alleviates the feeling of loneliness, in weak psyche, during the practice of exchange sex is also money, which adds more value to the exchange of energy in the relationship, money is not obtained with the company of friends, the problem is that in general the company that gets the sex worker in the practice of his profession with clients is of poor quality, in some cases clients are of such poor quality that it would be preferable to endure loneliness, that customers of poor quality (unattractive, bored, or without characteristics of the fantasies of desire). Another problem is that the customer of the sex worker is focused on obtaining pleasure and happiness for themselves, not for the sex worker, also the women take longer and it is more difficult to achieve orgasm, so the client usually gets the orgasm and with it partial happiness, total or supra-happiness, while the sex worker does not obtain the orgasm that is to say they do not obtain happiness.

The psyche of the sex worker is in some cases a weak ego and therefore intrapsychic conflict or comorbidity with psychiatric illnesses (affective disorders such as depression, bipolar affective disorder, anxiety disorders, personality disorders, substance use) make it harder to obtain happiness.

The sex worker generally gets a high salary for the practice of their profession, with the money you do not directly get the happiness, with the money you can buy happiness if used properly, man for example can get high quality orgasms 
(attractive people), women with the stability that money gives can get orgasms from a person they love, without needing to be with someone they do not love, because of financial need, however spending money on substance use or spending money everyday life means that sex worker must continue to work permanently in order to pay for the consumption of substances or expenses of daily life, so that high income, in general, is not well managed and does not generate permanent stability as a early retirement plan. Other problem is that the physical attractiveness diminishes with the age so that the exchange sex can not be practiced with high generation of money for unlimited time. The money achieves happiness because it guarantees or at least facilitates the subsistence of the offspring.

\section{Psychiatric Comorbidities in Exchange Sex. Sex Worker Have a Psyche with Advantages and Disadvantages}

\subsection{Advantages of the Psyche of Sex Worker}

At first sight it would seem that sex worker have a strong psyche, be willing to perform such humiliating and degrading work, in practice (low quality, unattractive clients, who seek their own satisfaction and not the satisfaction of the sex worker) can only be possible with very strong psyche. Many people perform very hard jobs to survive and raise their quality of life, but income as a sex worker with the disadvantages of the job and social discrimination must be supported by a very strong psyche or with the help use of substance, as is very often the case.

Actuelly many sex workers tolerate the exercise of their profession with substance use or to afford the consumption of substances [7]. Substance use may be due to pleasure or to decrease the symptoms of a mental illness like depression.

Being willing to perform a job as difficult as exchange sex is a symptom of a weak psyche, which is difficult to satisfy, it occurs in a large number of personality disorders (histrionic, narcissistic, borderline, antisocial). The lack, the feeling of emptiness, the dissatisfaction, the constitutional frustration is partially filled with the company of people, so the sex worker try to fill a feeling of constitutional void with the company of the clients and at the same time they get money for it.

\subsection{The Satisfaction of Sadism through Exchange Sex}

Sex worker with antisocial personality disorders or other personality disorders with violent drives, use exchange sex to discharge anger, frustration, dissatisfaction, hatred, resentment over their clients, swindling them, assaulting them psychically, verbally, sexually or economically during the practice of the profession, antisocial men can commit crimes (robbery, theft, homicide) but women with antisocial personality disorders [8], tend to perform more subtle sadistic practices such as humiliation. 


\subsection{The Satisfaction of Masochism through Exchange Sex}

Sex worker with weak psyche and intrapsychic conflicts self-attack with the practice of exchange sex, repair feelings of guilt, or satisfy masochistic drives with the humiliating practice of the job. In some cases the sex worker had traumatic childhoods with dysfunctions, sexual, psychological, verbal, physical abuse, neglect, emotional deprivation, so during the practice of exchange sex they try to repair that traumatic experience in life by letting themselves be humiliated by clients to self-punish themselves for the fantasy of self-blame that they feel (they think consciously or subconsciously: if my family attacked me I must be a very bad person, it's fine that clients also humiliate and attack me), or in some cases without a real history of abuse, ideas or perceptions of aggression can be found in the family, or act as a victim, or simply have masochistic drives without a traumatic history in the patients.

The clients satisfy on one hand their sexual erotic drives with the sex worker when obtaining the orgasm, but at the same time they satisfy their sadistic impulses for the frustration that they are constantly receiving from the environment (some men think consciously or subconsciously: I have to exchange a lot of energy or money for sex, when I should get that for free without spending energy), so the act is also aggressive, the client discharge with aggression all his frustration over the sex worker.

\subsection{Satisfaction of the Histrionics in Exchange Sex}

Sex worker satisfy their histrionics, porn stars, in the exercise of their profession, their need for attention is satisfied by the people who admire them in the exercise of their profession (clients) or with the attention they receive from people who reject their profession.

\subsection{The Satisfaction of the Economic Deficiencies through Exchange Sex}

Sex worker are generally poor women, with low socioeconomic income and deficient academic education levels. There are also sex worker with high educational levels (some countries where those academic degrees do not offer the quality of life they want and prefer practice exchange sex to raise the quality of life. Sometime the practice of exchange sex in poor, underdeveloped countries is due to social and economic conditions, where the only way of subsistence for sex worker and their families is through exchange sex. In some cases there are alternatives jobs to survive them and their families but with the practice of exchange sex they can get higher quality of life than other alternative Jobs [9].

\subsection{Repression of Sexual Enjoyment during the Practice of Exchange Sex by Women}

Sex worker in some cases repress their sexuality, sexual enjoyment during the practice of their profession to protect themselves from partial happiness, total happiness or supra-happiness, fear that with the orgasm they get from their 
clients, they will fusion emotionally. Put the libido to his clients fall in love with their clients is very risky, since the client could not repay that love which would generate a frustration, pain, suffering in the sex worker. Because of that fear of falling in love and not being reciprocated, sex worker repress the little possibility of happiness that they might receive in some cases with high-quality clients (attractive). So in theory would be that women learn as well as men to get partial happiness (orgasm of people who are not in love) without falling in love with the person with whom have sex, the falling in love should be planned between both so that frustration does not occur, however it is difficult to implement. Another problem is that although both fall in love with each other simultaneously, the love in one of the two could last less than the other member so it would again be generated frustration, something risky and difficult to implement in practice.

\section{Difference between Men and Women to Obtain Total Happiness or Supra-Happiness}

Men need a higher sexual frequency to stay happy or supra-happy permanently. The sexual frequency should be with attractive people or the person you are in love with.

Women need a lower sexual frequency to stay happy or supra-happy permanently. The sexual frequency should be with attractive people or the person you are in love with.

There are other variables that play a fundamental role such as money and secondary roles such as intelligence (cognitive, emotional, social, etc.) in obtaining happiness or supra-happiness.

In women, happiness also depends on whether the biological father of the offspring have high quality (physical attractiveness is generally synonymous with physical health) and that the biological father or caretaker father remains to guarantee the subsistence of the offspring, which is why money and security also play an important role in a woman's happiness, and happiness does not only depend on obtaining an orgasm from some high-quality (attractive) person.

For women to get an orgasm of a high quality object (attractive person) is not enough, if so, men would be concentrated all day in gyms and cosmetic surgeries to improve their physical attractiveness, and not concentrated in study and work for get money and thus be able to exchange with that money (energy) for receiving orgasms from women.

\subsection{Duration of Love}

The love lasts only 6 months [10], the massive discharge of dopamine in the prefrontal cortex that generates that feeling of falling in love (vegetative symptoms, stomach, nervousness, euphoria) lasts approximately 6 months, then decreases until disappearing, in those 6 months it should be enough for procreation, which is the final biological goal of falling in love, it would be very costly biologically to spend more than 6 months of energy in procreation, with procr- 
eation and children there is a discharge of oxytocin and vasopressin which can prolong the infatuation about 5 years for each child, this promotes that the father remains to guarantee the subsistence of the children. Fortunately the libido can be removed from an object and placed immediately on some other object (falling in love with someone else immediately). It should be clear that in almost all people falling in love lasts a short time, that people should not have any kind of expectation of obtaining a lifetime of total happiness or supra-happiness with the same person.

\subsection{Who Are Happier? Or Better Said, Who Are Less Unhappy Men or Women?}

It is necessary to clarify that partial happiness, total happiness or supra-happiness only lasts a short time, it is the normal functioning of human beings, they must always be frustrated and unhappy to be able to have life drive, motivations, volitions, a permanently happy person would not have any motivation to improve, to survive, it would be satisfied and it would not do anything else. That is why happiness has to be obtained frequently in a repeated way.

It is difficult to objectively determine who are happiest between men or women. An indicator would be the incidence and prevalence of mental illnesses in men is more frequent the consumption of substances and addictions (alcohol, probably to mitigate the symptoms of anxiety or depression and suffering due to the unhappiness generated by the inability to obtain orgasms of the person you love, or orgasms of many people are high quality, attractive, you need a lot of money or energy for it), while in women it is more frequent affective disorders (frustration generated by obtaining orgasms of bad quality objects, unattractive people, or that the biological father or caregiver does not have money or intelligence to guarantee the best subsistence of the children).

It could be argued that women are less unhappy than men because they have less sexual drive than men, need less sex, less orgasms from people they love to partially decrease unhappiness, men on the other hand have a much greater sexual drive than women need orgasms from people they love or from high-quality objects (attractive people) to temporarily decrease unhappiness, so men are exposed to more constant frustration than women, so men in theory should be more unhappy.

The only advantage of men is that they obtain orgasm is more easily than women, so theoretically they could temporarily decrease unhappiness more easily than women without investing almost all of their energy in obtaining money to be exchanged for sex with sex worker or in a classic normal couple relationship.

Women theoretically on the other hand should concentrate all their energy on obtaining orgasms from men they love or high-quality objects (attractive people).

\subsection{Reciprocity of Love with the Person Who Loves to Obtain Happiness}

When love is reciprocated from the partner it provides more security and stabil- 
ity for the members of the couple who love each other, however it is not necessary that the person you are in love with correspond love to obtain happiness, it is enough that you get an orgasm of the person you are in love with, a good example is the couple's relationships where only one member of the couple is happy in the relationship because they get orgasms from the couple they love, however the other member is not in love, is dissatisfied with the relationship and that does not prevent the other member with a narcissistic psyche from obtaining happiness.

\section{Conclusions}

Hypotetical conciderations to obtain partial happiness, total happiness and supra-happiness:

Men to obtain partial happiness and supra-happiness could:

- Produce as much money as possible in order to obtain orgasms as often as possible from the most attractive people possible (high quality objects).

- In second place they have also to perform physical exercises and aesthetic surgeries to improve their physical attractive, which plays a fundamental role in obtaining orgasms of people who are in love (high quality objects and/or where you have putting the libido).

Women to obtain partial happiness and supra-happiness could:

- Perform physical exercises and aesthetic surgeries to improve their physical attractive, which plays a key role in obtaining orgasms of attractive people and/or those who are in love (high quality objects and/or where you have putting the libido).

- Second, to produce as much money as possible in order to obtain financial independence and guarantee the survival of the children without having to depend on unattractive men or demanding monogamous relationships. With money, women can freely and independently obtain orgasms from people they are in love with (objects where the libido is placed) or attractive people (high quality objects).

\section{Declaration}

I declare that I condemn in the most categorical way the slavery or forced practice of any act in any human being. In the same way, I respect the profession that each person decides to exercise voluntarily and free will. I also respect the legal statutes of each country for the free practice or criminalization of some work activity.

\section{Conflicts of Interest}

The author declares no conflicts of interest regarding the publication of this paper.

\section{References}

[1] Weisfeld, G.E. (2004) Current Evolutionary Perspectives on Adolescent Romantic 
Relations and Sexuality. Journal of the American Academy of Child \& Adolescent Psychiatry Home, 43, 11-19. https://doi.org/10.1097/00004583-200401000-00010

[2] Wix, R.J. and Uribe, E. (2021) Benzodiazepines, Amphetamines, Testosterone, and Sildenafil as New Candidate Drugs for Sexual Interest, Desire and/or Arousal Disorder. Current Psychopharmacology, 10, 1-10. https://doi.org/10.2174/2211556010666210301144022

[3] Gaskins, A.J. (2018) Predictors of Sexual Intercourse Frequency among Couples Trying to Conceive. The Journal of Sexual Medicine, 15, 519-528. https://doi.org/10.1016/j.jsxm.2018.02.005

[4] Wix-Ramos, R.S.F. (2018) Mathematical Formula of Sex, Love, Economy and Happiness. Therapy and Psychiatric Analysis of the Economy and the Financial Markets. Archives of Depression and Anxiety, 4, 3-17. https://doi.org/10.17352/2455-5460.000027

[5] Rio, L.M. (1991) Psychological and Sociological Research and the Decriminalization or Legalization of Prostitution. Archives of Sexual Behavior, 20, 205-218. https://doi.org/10.1007/BF01541945

[6] Wix-Ramos. (2016) Transference and Counter Transference between Students and Professors: The Role of Gender or Motherhood in this Psychodynamic Phenomenon. Annals of Psychiatry \& Mental Health, 4, 1073.

[7] Aldridge, R.W. (2018) Morbidity and Mortality in Homeless Individuals, Prisoners, Sex Workers, and Individuals with Substance Use Disorders in High-Income Countries. Lancet, 391, 241-250. https://doi.org/10.1016/S0140-6736(17)31869-X

[8] Beauchaine, T.P.-K. (2009) Multifinality in the Development of Personality Disorders: A Biology $\times$ Sex $\times$ Environment Interaction Model of Antisocial and Borderline Traits. Development and Psychopathology, 21, 735-770. https://doi.org/10.1017/S0954579409000418

[9] Love, R. (2015) Street Level Prostitution: A Systematic Literature Review. Issues in Mental Health Nursing, 36, 568-577. https://doi.org/10.3109/01612840.2015.1020462

[10] Fisher, H.E., et al. (2016) Intense, Passionate, Romantic Love: A Natural Addiction? How the Fields That Investigate Romance and Substance Abuse Can Inform Each Other. Frontiers in Psychology, 7, 687. https://doi.org/10.3389/fpsyg.2016.00687 


\section{Appendix}

\section{Partial Happiness \\ Get an orgasm from someone who is not in love with}



Figure A1. The figure shows how Partial Happiness is reached: Obtaining orgasms from as many people as possible as often as possible to generate happiness, pleasure and satisfaction. That happiness is only temporary, the original dissatisfaction and lack of the human psyche has to be filled and constantly satisfied with that temporary happiness.

Total Happiness

Get an orgasm from someone who is in love with



Figure A2. The figure shows how Total Partial Happiness is obtained: Obtaining orgasms of the person you are in love with (objects where you have the libido) as often as possible to generate happiness, pleasure and satisfaction. That happiness is only temporary, the original dissatisfaction and lack of the human psyche has to be filled and constantly satisfied with that temporary happiness.

\section{Supra-Happiness}

Get orgasm from someone who is in love and with many other attractive people at the same time simultaneously.



Figure A3. The figure shows how you get Supra Happiness: Obtaining orgasms of the person you are in love with (objects where you have the libido) and with many other attractive people at the same time simultaneously, as often as possible to generate happiness, pleasure and satisfaction. 
The figure shows how you get Supra-Happiness: I have defined as the discharge of sexual drive on an object where you have the libido or several objects where the libido is placed simultaneously or objects where they are not put the libido but good quality (get an orgasm with someone you are in love with or with several people you are in love with or people you are not in love with but of high quality, that is, attractive, interesting, with good performance in sexual practice, with money or whatever the fantasy of desire). That happiness is only temporary, the original dissatisfaction and lack of the human psyche has to be filled and constantly satisfied with that temporary happiness. 